\title{
Can the Multianvil Apparatus Really be Used for High Pressure Deformation Experiments?
}

W.B. Durham and D.C. Rubie
RECEIVED

MAY 301996

OSTI

This paper was prepared for submittal to AGU Monograph Series

1996 U.S./ Japan Symposium on High Pressure, High Temperature Research

January 15-18, 1996, Maui, Hawaii

April 24, 1996

This isa preprint of a paper intended for publication in a journal or proceed ings. Since changes may be made before publication, this preprint is made available with the understanding that it will not be cited or reproduced without the permission of the author. 
This document was prepared as an account of work sponsored by an agency of the U.nited States Government. Neither the United States Government nor the Lniversity of California nor any of their empiovees. makes any warranty. express or implied. or assumes any legal liability or responsibility for the accuracy. completeness, or usefulness of any information. apparatus. product. or process disciosed. or represents that its use would not infringe privately owned rights. Reference herein to any specific commercial products. process. or service by trade name. trademark. manuiacturer. or otherwise, does not necessariiv constitute or imply its endorsement. recommendation. or favoring by the Lnited States Government or the University of California. The views and opinions of authors expressed herein do not necessarily state or reflect those of the Linited States Government or the University of California. and shall not be used for advertising or product endorsement purposes. 


\title{
Can the Multianvil Apparatus Really Be Used for High-Pressure Deformation Experiments?
}

\author{
W. B. Durham $\div$ and D. C. Rubie \\ Bayerisches Geoinstitut, Universität Bayreuth, 95440 Bayreuth, Germany; +49 921 55-3700 \\ ‡ permanent address: Earth Sciences Dept., Lawrence Livermore National Laboratory, \\ Livermore, CA 94550, U.S.A.; 510-422-7046; durham1 @LLNL.GOV
}

\begin{abstract}
Past claims of the suitability of the MA-8 multianvil press as a deformation apparatus may have been overstated. On the basis of measurements of final octahedron size and of guide block displacement as a function of time, using the 10/5, 14/8, and 18/11 assemblies (octahedron edge length in $\mathrm{mm} /$ truncation edge length in $\mathrm{mm}$ ) with $\mathrm{MgO}$ octahedra and pyrophyllite gasketing, it appears that at run conditions of interest to most researchers there is no appreciable time-dependent creep of gaskets and octahedra. All inelastic deformation occurs at rather low pressures: below about $10 \mathrm{GPa}$ for the $10 / 5,7 \mathrm{GPa}$ for the $14 / 8$, and $6 \mathrm{GPa}$ for the $18 / 11$ assemblies, with substantial uncertainties in these pressures. Above these limits all deformation of the pressure medium is elastic. Pressure stepping as a means of increasing the inelastic deformation rate of a sample is probably ineffective. Displacement measured at the guide blocks, previously believed to indicate deformation of the gaskets and octahedron, appears now to be unrelated to creep of these components. The calibrations have not been exhaustive and there is considerable scatter in some of the size measurements, so the above conclusions are not unequivocal. The calibrations do not exclude the possibility of deformation of a few tens of microns after the attainment of high pressure. Efforts to impose permanent shape change to samples at high pressure and temperature simply by relying on long run durations must be viewed with skepticism. There may be possibilities for deformation in the multianvil apparatus if materials of contrasting elastic modulus are used to differentially load a sample during pressure stepping.
\end{abstract}




\section{Introduction}

Recent papers have suggested that the slightly nonhydrostatic environment of the largevolume high-pressure multianvil (MA-8) apparatus might be exploited to investigate the deformation of mantle materials in situ at high pressures and temperatures [Liebermann and Wang, 1992]. Important experimental results have also been published that purport to have imposed significant amounts of permanent strain to samples at high pressures and temperatures to produce high-pressure faulting (as related to deep-focus earthquakes) [Green et al., 1990] and to measure the activation volume for creep in olivine [Bussod et al., 1993]. The ability to deform materials at mantle conditions represents an important experimental advance that is of interest to many geophysicists.

There is convincing evidence that differential stresses can exist in the multianvil cell at high pressures and temperatures. We ourselves have produced in the multianvil cell the scalloped remnant olivine grains and elongated $\beta$-phase grains during the $\alpha$ to $\beta$ phase transformation that Vaughan et al. [1984] and Green [1986], in studies of the $\alpha$ to $\gamma$ transformation, have shown identify a direction of maximum compressive stress when the transformation takes place under nonhydrostatic conditions (Figure 1). However, the evidence that such differential stresses endure over macroscopic strains is much more circumstantial. The sample assembly in the multianvil apparatus typically undergoes high strain during initial pressurization, and differentiating permanent strain that occurs at high pressure from that which occurs during initial pressurization can be problematic. We have been attempting to further develop multianvil techniques with the aim of performing deformation experiments under pressure-temperature conditions of the earth's mantle, but in the course of trying to determine the true amount of imposed deformation at high pressure and temperature, a very different picture has emerged than previous studies have suggested. The purpose of this short paper is to bring expectations into line with reality as regards 
using the multianvil apparatus as a creep apparatus. We do not attempt to provide a rigorous calibration of the mechanical behavior of the apparatus.

\section{Measurements}

Experiments described here were performed using the two MA-8 multianvil presses at the Bayerisches Geoinstitut in Bayreuth, Germany. A general description of the experimental configuration is given by Ito et al. [1984] and Liebermann and Wang [1992] and specific details of the pressure calibrations and the samples assemblies used can be found in Rubie at al. [1993a, b] and Canil [1993]. We used three common pressure cell configurations: 18/11, 14/8, and 10/5, where the notation is octahedron edge length in $\mathrm{mm} /$ truncation edge length in $\mathrm{mm}$. Machined octahedra consisting of sintered $\mathrm{MgO} / 5 \% \mathrm{CrO}_{2}$ provided the confining medium and gaskets were made of pyrophyllite. High-temperature sample assemblies used a $\mathrm{LaCrO}_{3}$ furnace surrounded by an insulating sleeve of $\mathrm{ZrO}_{2}$. In most cases standard sample assemblies were used and only in a few experiments were assemblies used that contained $\mathrm{Al}_{2} \mathrm{O}_{3}$ pistons designed specifically to stress the sample [e.g., Green et al., 1990; Bussod et al., 1993].

Bussod et al. [1993] have presented data suggesting that the sample strain, octahedron strain and the relative displacement of the multianvil guide blocks are all related in multianvil experiments. If this were the case, the sample strain could be monitored in real time simply by measuring the guide block displacement. To test this possibility more rigorously, we have attempted to determine the amount of deformation that takes place under pressure by making two types of measurements: (1) final octahedron size after depressurization, as indicated by benchtop measurements of the distance between the four pairs of opposite parallel faces; and (2) relative displacement of the two guide blocks (Figure 2). Closure of the guide blocks is monitored by a single direct current differential transformer displacement transducer whose body is rigidly attached to one guide block and whose core moves rigidly with the other guide block. Both octahedron size 
and guide block displacement were measured at a range of pressures, temperatures, run times, and cell configurations. Many of the measurements were made during routine experiments performed in the multianvil laboratory at the Bayerisches Geoinstitut in the course of other investigations.

\section{Observations}

Octahedron size vs pressure. The $\mathrm{MgO}$ octahedra have an initial porosity of about $20 \%$ and interfacial distances for the three different sizes of $14.6 \mathrm{~mm}, 11.3 \mathrm{~mm}$, and $8.2 \mathrm{~mm}$, respectively, all $\pm 0.05 \mathrm{~mm}$. Final octahedron sizes for the three different assemblies are plotted as a function of pressure in Figure 3. The run conditions are not uniformly distributed in pressure-temperature space, but tend to cluster where researchers chose to perform their experiments, so attention must be paid to the temperature labels attached to each point. For example, for the $10 / 5$ assemblies (Figure 3a), the highest pressure runs are also the highest temperature runs; the significant decrease in size from 18 to $19 \mathrm{GPa}$ can be caused (based on Figure 3 alone) by either higher temperature, higher pressure, or both. Run times are not shown. Except for the few longer runs performed specifically for the purposes of creep calibration (see below), run times vary from a few seconds to 6 hours.

No trend is obvious in the $18 / 11$ assembly above $6 \mathrm{GPa}$ (Figure 3c), data are sparse and scattered for the 14/8 (Figure 3b), and the strongest trend for the 10/5 (Figure 3a) cannot distinguish the effect of pressure from that of temperature. Replotted vs temperature, with pressure as an attached label (Figure 4) reveals a weak but consistent trend for all three configurations of decreasing octahedron size with increasing temperature. The trends might be less scattered were the 14/8 and 18/11 size measurements made by Bussod et al. [1993] not included (those in Figures 3 and 4 without error bars). Those sizes appear to be systematically lower than those measured by us, but without any a priori reason for excluding those data, we include them in the figures. 
Taking the temperature trend in Figure $4 \mathrm{c}$ as a correction to the data in Figure $3 \mathrm{c}$ produces a clearer indication that the size of $18 / 11$ assembly is independent of pressure (Figure 5) above 6 GPa. The same correction cannot be applied for the 10/5 data because of their biased locations in pressure-temperature space.

The perspective provided by two points at $1500^{\circ} \mathrm{C}$ and 7 and $8 \mathrm{GPa}$ in Figures $3 \mathrm{~b}$ and $4 \mathrm{~b}$ deserves special note. These experiments were performed for the sole purpose of creep calibration, that is, specifically to determine the effectiveness of the pressure ramping technique [Bussod et al., 1993] to produce an accelerated deformation rate. (A note in the Figure $3 \mathrm{~b}$ caption explains why the two data points are displaced with respect to the other points in the plots.) The two assemblies were prepared simultaneously and run sequentially in the same multianvil press. Pressure-temperature-time histories differed only by the pressure ramp: both were taken to their run pressures ( $7 \mathrm{GPa}$ in the one case; $8 \mathrm{GPa}$ in the other) at the same rate and then heated to $1500^{\circ} \mathrm{C}$. Both were held at highest $(P, T)$ for 30 minutes, then quenched to room temperature, and finally depressurized at identical rates. Not only were the sizes of the two octahedra indistinguishable, but the fact that they experienced relatively low (for the 14/8 assembly) pressures where inelastic compaction might be expected to be higher than at more elevated pressures did not bode at all well for the use of the pressure ramping technique, or the multianvil apparatus in general, in deformation experiments.

Guide block displacement vs time. Guide block displacement vs. time curves (Figure 6) give the distinct impression that creep occurs while the assembly is under pressure. For the duration of typical runs, usually a few minutes to a few hours at constant pressure and temperature, the displacement transducer reveals a steady, if not slightly decelerating rate of advancement of the guide blocks of $10 \mu \mathrm{m}$ or more per hour. Were this displacement rate imposed on a typical sample of length $1-2 \mathrm{~mm}$, the strain rate would be $10^{-5}$ to $10^{-6} \mathrm{~s}^{-1}$ (for instance, as 
Bussod et al. [1993] have suggested), which is within the range of strain rates of conventionai laboratory deformation experiments in geophysics. In no case, however, have we ever observed the rate of guide block advancement to cease decelerating. Carried to longer and longer run times, the rate of advancement can be seen to slow to insignificantly low values (for deformation experiments), and finally, after about 24 hours duration, to cease.

It is important to point out that the fastest guide block advancement rates of $>10 \mu \mathrm{m} / \mathrm{h}$ are not necessarily inconsistent with the observations of final octahedron size shown in Figures 3 and 4. This becomes apparent when the fine displacement scales of Figure 6 are compared with the much coarser vertical scales of Figures 3 and 4 . It would not be difficult to hide, say, $0.05-0.1$ $\mathrm{mm}$ of inelastic deformation in the scatter of Figures 3 and 4 . The lack of a demonstrable decrease in octahedron size during pressure ramping, where guide block displacement rates are closer to 100 $\mu \mathrm{m} / \mathrm{h}$, can be seen in hindsight to indicate that inelastic strain was an illusion. However, the implications of the near constant octahedron size could be easily overlooked given the steady, reproducible trace of guide block advancement vs time. The minute deceleration of the guide block advancement rate over the course of a short duration experiment could also be explained by gasket area increasing as octahedron and gasket extrude into the space between tungsten carbide anvils. However, only small decreases in guide block displacement rate can be explained by gasket area increase because the change in displacement rate must be proportional to the change in gasket area, which would presumably be related in a complex, but distinct, way to final octahedron size.

Another aspect of the behavior of the apparatus that can be misleading is the guide block response upon initial heating. In most runs, pressure is first raised to the desired level before the temperature is raised. Immediately upon heating, one almost invariably observes that the rate of guide block advance and oil pumping to the ram immediately speed up, indisputable evidence that the thickness of the octahedron and gaskets are decreasing. Prompt thermal expansion should have exactly the opposite effect on displacement, so presumably the shrinking comes from weakness of 
the respective materials at high temperatures. We have difficulty reconciling this observation with the behavior shown in Figures $3-6$. The weak negative dependence of final octahedron size upon temperature (Figure 4) is, at first glance, consistent with this idea because higher temperature usually causes materials to creep faster. However, if the sudden weakness in octahedron and gaskets occurs because of the higher temperature, one must question why the weakness is only short-lived even though high temperature persists. Spreading gasket area is not a satisfactory explanation for reasons given above. Work hardening of the $\mathrm{MgO}$ and pyrophyllite are difficult to prove and also do not provide a very satisfactory explanation because of the extreme magnitude of work hardening required. The very long duration experiment in Figure $6 \mathrm{~b}$ is very revealing in this regard. In that experiment, pressure was held constant at $12 \mathrm{GPa}$ for nearly 6 hours at room temperature before heating the sample chamber. In that experiment the prompt response to heating was a separation of the guide blocks. Acceleration in guide block closure did occur, but only after nearly one hour had elapsed. Thermal steady state at the octahedron and gaskets must have been reached in a few minutes, and certainly in less than an hour. It seems very unlikely, therefore, that the guide block closure indicated by the long-duration test in Figure $6 \mathrm{~b}$ was related to displacements at the octahedron. The effect of the heat pulse as it encounters the mass of the press is too complex even for a qualitative discussion. One can speculate over various explanations for a divergence of the guide blocks (e.g., higher thermal expansivity of the ram oil vs that of the steel surrounding it) as well as for an apparent closure (e.g., warming up and thermal expansion of the displacement transducer).

Further evidence that the high displacement rates shortly after heating are illusory is provided by the measurements of final octahedron size as a function of run duration for seven nearly identical 10/5 experiments shown in Figure 7. Those runs were carried out for relatively short durations of 35 minutes or less, the period during which apparent guide block displacement rates are most rapid (as fast as or faster than the initial stages of the curves in Figure 6). Figure 7 shows no tendency for the octahedron size to decrease with time. 


\section{Discussion and conclusions}

Upon initial pressurization in the multianvil apparatus there is considerable inelastic compaction of the octahedral pressure medium, but on the basis of the data in Figures $3-7$. significant inelastic compaction apparently ceases at pressures $P_{\text {crit }}$ that are well below most common experimental run pressures. For the $18 / 11,14 / 8$, and $10 / 5$ assemblies, we can identify approximate values of $P_{\text {crit }}$ of 6,7 , and $10 \mathrm{GPa}$, respectively (Figure 3). Excluding stressrelaxation tests, deformation experiments using the multianvil apparatus require that gaskets (and octahedron) creep at fixed pressure. The idea that gaskets creep in the multianvil apparatus [Bussod et al., 1993] seems to have its origin not in direct measurements of gasket thickness vs time, but rather in consistent observations of guide block displacement vs. time. Creeping gaskets is not the only explanation for guide block displacement, and since the observations in the previous section are incompatible with gasket creep at $P>P_{c r i t}$, either at fixed pressure or during pressure ramping, it must now be presumed that the gaskets do not creep. Therefore, until such time that there is direct evidence of gasket creep, previously published results based on the concept of creeping gaskets [Green et al., 1990; Bussod et al., 1993] must be viewed with skepticism, a point that we admit may lead to controversy.

The calibration measurements in this work are not exhaustive. Measurement scatter in some of the figures is very high. However, more rigorous calibration will require a major effort, for which no plans currently exist. The point in publishing this work now is not to settle the issue of creeping gaskets, but rather to bring to the attention of the community the possibility that they may not creep.

The ability to perform deformation experiments at extreme pressures is still a noble goal of geophysical research, and in fact we have not fully abandoned the possibility of doing such experiments in the MA-8 apparatus. We are currently exploring the idea of using materials of 
strongly contrasting elastic bulk moduli inside the $\mathrm{MgO}$ octahedron. With proper choice and arrangement of parts, low-magnitude pressure ramping can be exploited to impose a small displacement to a sample. For example, we calculate that if tungsten pistons are used (Figure 2), pressure ramping of $1 \mathrm{GPa}$ at some level above $P_{\text {crit }}$ should force an inelastic shortening of several tens of micrometers to any material located between the pistons. Special piston geometries can amplify this deformation to many tens of percent of strain in a sample [S. Karato, 1996, personal communication].

\section{Acknowiedgments}

The paper was written while the first author was on sabbatical leave at the Bayerisches Geoinstitut, and he gratefully acknowledges the financial support of the Alexander von Humboldt Foundation during that leave. We want to thank the following staff members, students, and guest researchers at the Geoinstitut for cooperating with our intrusive measurements of their MgO octahedra following their tests: B. Poe, C. Geßmann, S. Karato, L. Kerschhofer, R. Knoche, M. Schmidt, N. Ross, and S. Webb. Discussions with E. Ohtani and T. Sharp contributed materially to this work and are greatly appreciated. The first author acknowledges that his work was performed under the auspices of the U. S. Department of Energy by the Lawrence Livermore National Laboratory under contract W-7405-ENG-48. 


\section{References}

Bussod, G. Y., T. Katsura, and D. C. Rubie, The large volume multi-anvil press as a high P-T deformation apparatus, Pageoph, 141, 579-599, 1993.

Canil, D., in Short Course Handbook on Experiments at High Pressure and Applications to the Earth's Mantle, ed. by R. W. Luth, Mineral. Soc. Canada, Edmonton, pp. 197245, 1993.

Green, H. W. II, T. E. Young, D. Walker, and C. H. Scholz, Anticrack-associated faulting at very high pressure in natural olivine, Nature, 348, 720-722, 1990.

Green, H. W. II, Phase transformation under stress and volume transfer creep, in Mineral and Rock Deformation: Laboratory Studies (The Paterson Volume), Geophysical Monograph 36, ed. by B. E. Hobbs and H. C. Heard, American Geophysical Union, Washington, D.C., pp. 201-211, 1986.

Ito, E., Takahashi, E., Matsui, Y.. The mineralogy and chemistry of the lower mantle: an implication of the ultrahigh-pressure phase relations in the system $\mathrm{MgO}-\mathrm{FeO}-\mathrm{SiO}_{2}$, Earth Planet. Sci. Lett., 67, 238-248, 1984.

Liebermann, R. C. and Y. Wang, Characterization of sample environment in a uniaxial split-sphere apparatus, in High-Pressure Research: Application to Earth and Planetary Sciences, ed. by Y. Syono and M. H. Manghnani, Terra Scientific, Tokyo, pp. 19-31, 1992.

Rubie, D. C., C. R. Ross II, M. R. Carroll, and S. C. Elphick, Oxygen self diffusivity in $\mathrm{Na}_{2} \mathrm{Si}_{4} \mathrm{O}_{9}$ liquid up to $10 \mathrm{GPa}$ and estimation of high-pressure melt viscosities, Am. Mineral., 78, 574-582, 1993a.

Rubie, D. C., S. Karato, H. Yan, and H. St. C. O'Neill, Low differential stress and controlled chemical environment in multianvil high-pressure experiments, Phys. Chem. Mineral., $20,315-322,1993 b$.

Vaughan, P. J., H. W. Green, and R. S. Coe, Anisotropic growth in the olivine-spinel transformation of $\mathrm{Mg}_{2} \mathrm{GeO}_{4}$ under nonhydrostatic stress, Tectonophysics, 108, 299-322, 1984. 


\section{Figure Captions}

Figure 1. Optical photomicrograph of $\beta$ phase transformed from $\mathrm{Mg}_{1.8} \mathrm{Fe}_{0.2} \mathrm{SiO}_{4}$ olivine. The $\beta$ phase growth rate is fastest in the direction of the maximum compressive stress [Vaughan et al., 1984; Green, 1986].

Figure 2. Schematic sketch of the experimental setup for MA-8 multianvil deformation experiments. The two guide blocks ( $\mathrm{A}$ and $\mathrm{B}$ ), which contain the outer set of six anvils, are compressed in a uniaxial press up to a load of 500-1000 tonnes. Also shown are four of the eight inner anvils, consisting of WC cubes, and the pressure assembly consisting of a $\mathrm{MgO}$ octahedron. In previous attempts to perform deformation experiments, the sample was located uniaxially between hard pistons (e.g. $\mathrm{Al}_{2} \mathrm{O}_{3}$ ) within the $\mathrm{MgO}$ octahedron. Measurements presented in this study consist of (1) measurements of the final octahedron size after experiments as a function of sample pressure, sample temperature, and experimental run duration; and (2) guide block displacement (arrow) as a function of experimental run time.

Figure 3. Final octahedron size, as indicated by the mean and total scatter (error bars) of distances between the 4 pairs of parallel faces, as a function of maximum run pressure for the (a) $10 / 5$, (b) $14 / 8$, (c) $18 / 11$ multianvil assemblies (the notation is octahedron edge length in $\mathrm{mm} /$ tungsten carbide cube truncation edge length in $\mathrm{mm}$ ). Most of the points without error bars are taken from Bussod et al. [1993]. Points are labeled with maximum run temperature. One point in (a) and two points in (b) labeled with asterisks $(*)$ were special calibration runs (see text). Their final size is anomalously large because they were constructed without the usual cardboard and teflon tape backing pyrophyllite gaskets. For most of the points, run times (not given) varied from several seconds to 3 hours. Note that points are not very evenly distributed in $(P, T)$; in particular, note in (a) that the runs at highest $P$ are also the runs at highest $T$. The labels $P_{\text {crit }}$ are our identification of the pressures at which inelastic compaction ceases (see text). 
Figure 4. Same data as in Figure 3, but plotted as final octahedron size vs maximum run temperature for the (a) 10/5, (b) 14/8, and (c) 18/11 assemblies, with points labeled according to maximum run pressure. The straight dashed line in (c) is a least squares fit to all points for which $\mathrm{P}>P_{\text {crit }}(6 \mathrm{GPa})$.

Figure 5. 18/11 data from Figure $3 \mathrm{c}$ corrected for temperature according to the linear trend in Figure 4c.

Figure 6. Guide block advancement as measured by a displacement transducer located between guide blocks as a function of elapsed time for the (a) 10/5, (b) 14/8, and (c) 18/11 assemblies. For run durations of a few hours, there appears to be a nearly steady rate of advance, suggesting that the gaskets and octahedron are creeping. However, over very long run times $(a, b)$, the guide block advancement rate drops to insignificant levels. Note the behavior of displacement immediately after heating in the long duration 14/8 run in (b). The prompt response was an (apparent) widening of the inter-guide block distance by $4 \mu \mathrm{m}$, followed after 40 minutes by an (apparent) resumption of closure. Because temperatures in the neighborhood of the octahedron and gaskets reach steady-state in much less than 40 minutes, we believe that the most of the displacement in this curve (and by extension all the other curves) did not result from creep of the gaskets or octahedron.

Figure 7. Final octahedron size as a function of run time for six $10 / 5$ runs carried out with identical sample assemblies at identical pressures and temperature by the same researcher (N. L. Ross) on the same multianvil press. The lack of size change with run time even over a range of short duration runs is another argument in support of the displacements shown in Figure 6 not being related to octahedron size. 


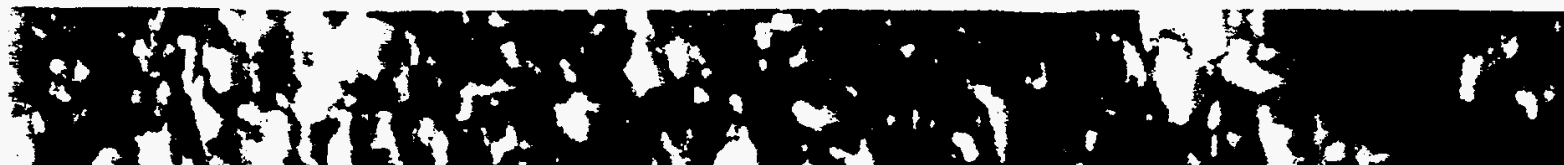
anget

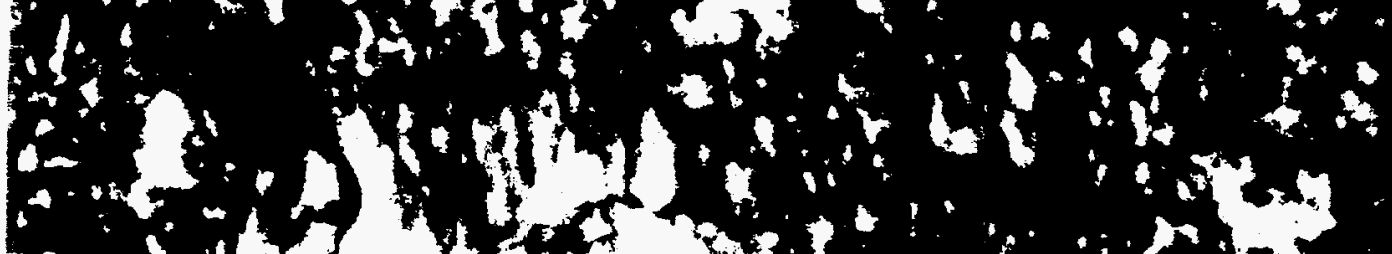

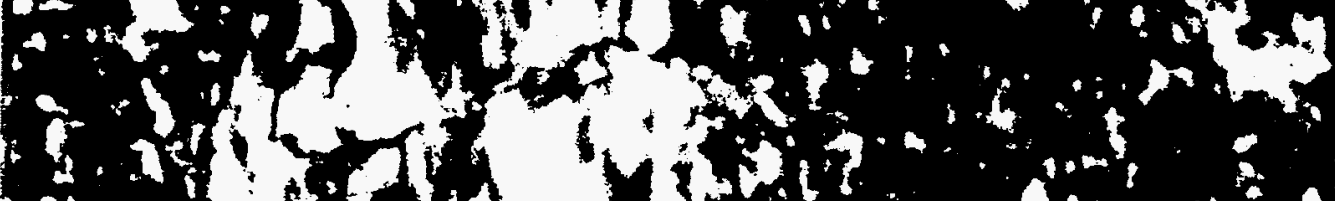

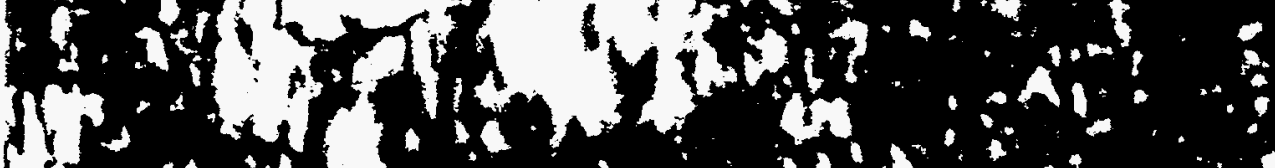
H.t.

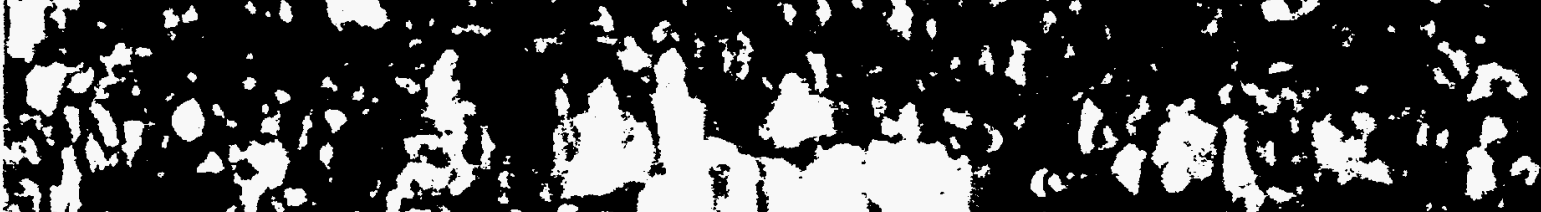

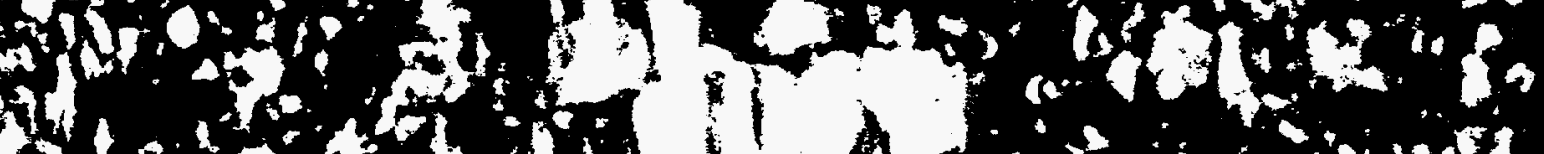

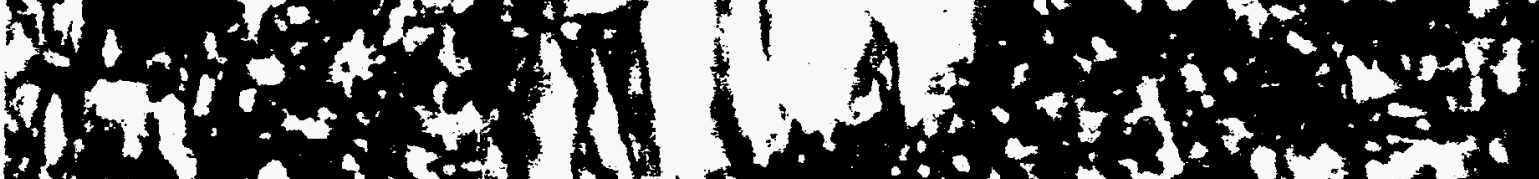

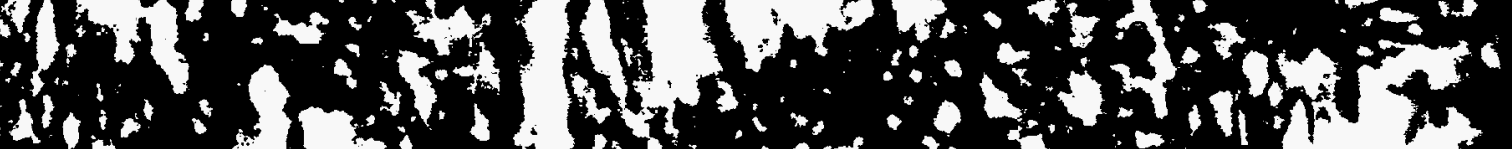

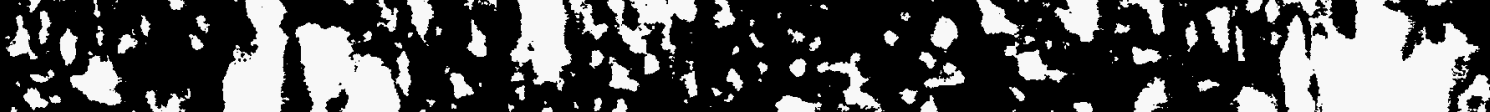

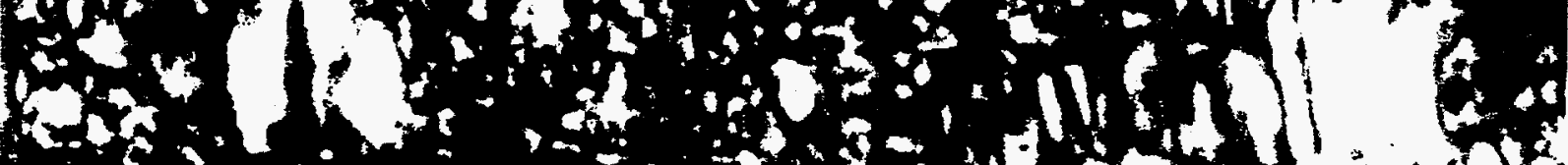

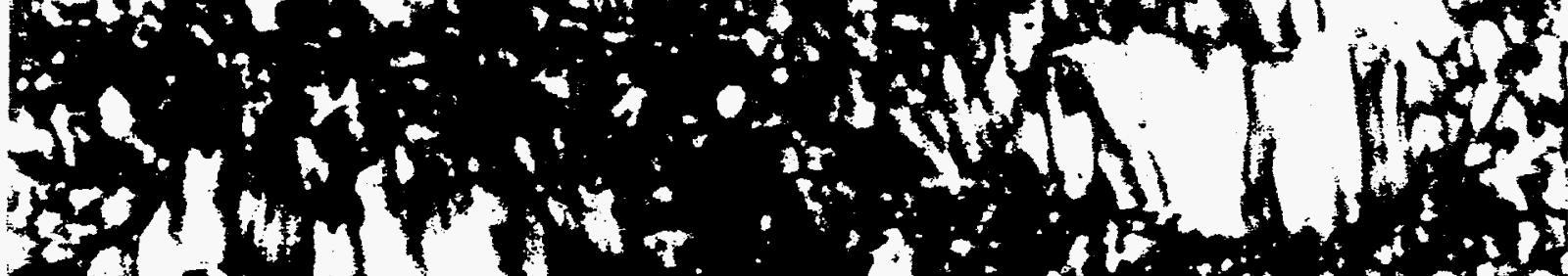

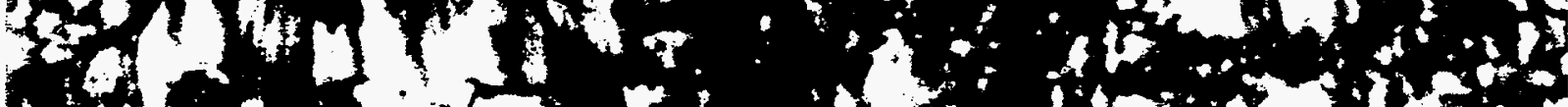

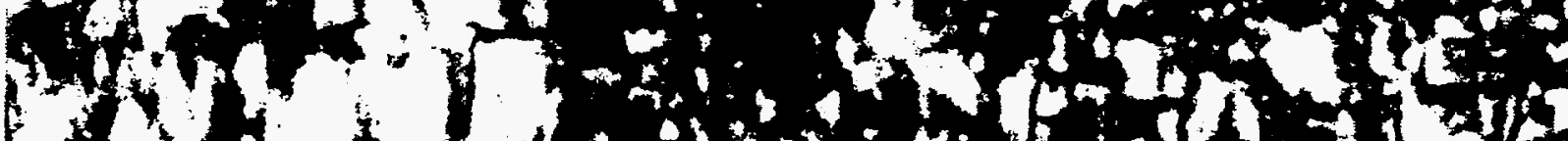

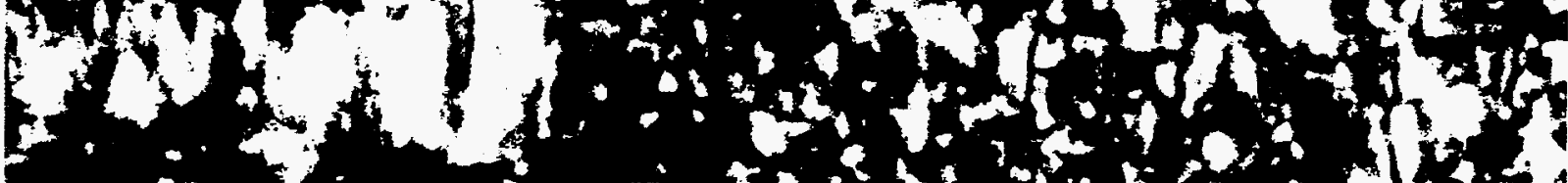

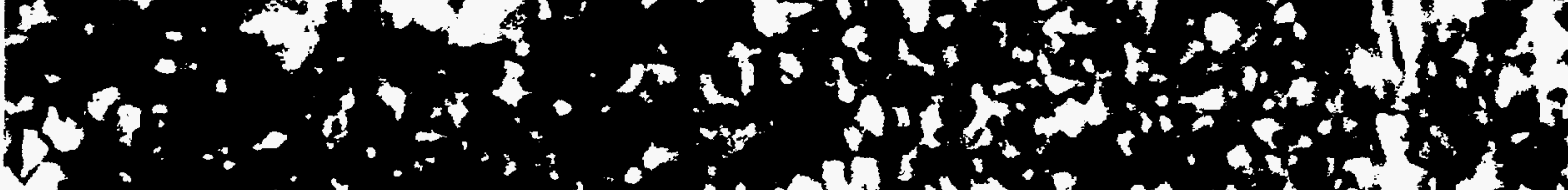

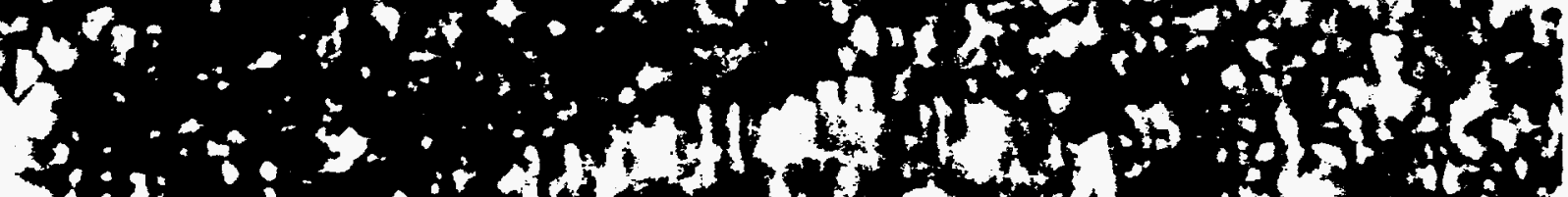

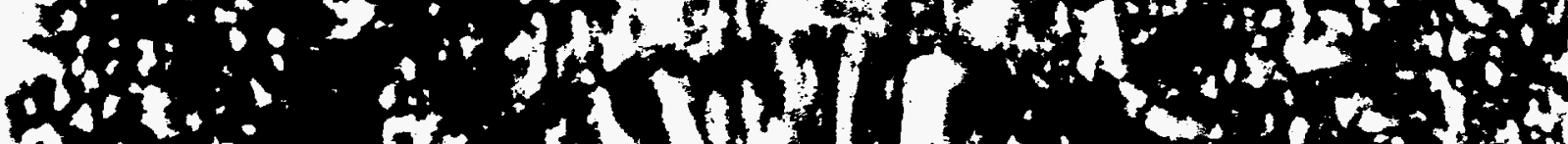

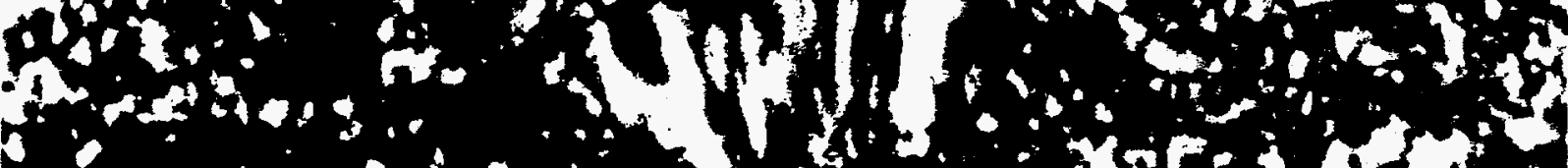

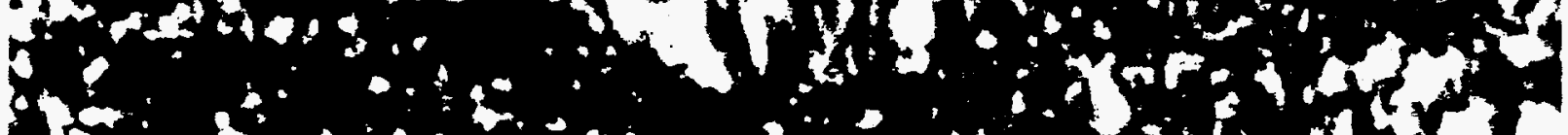
a

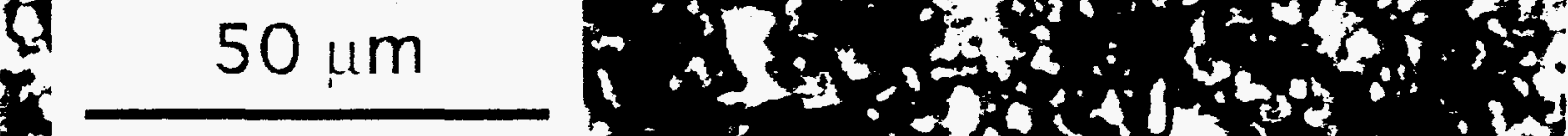

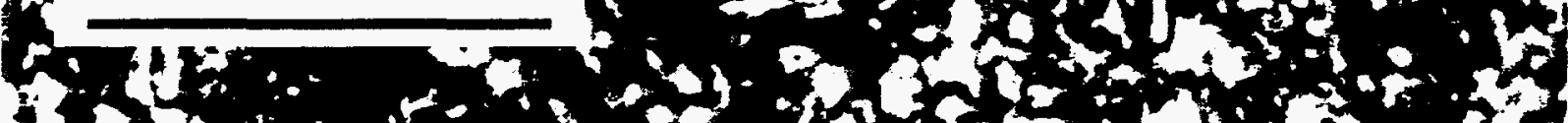
3. 


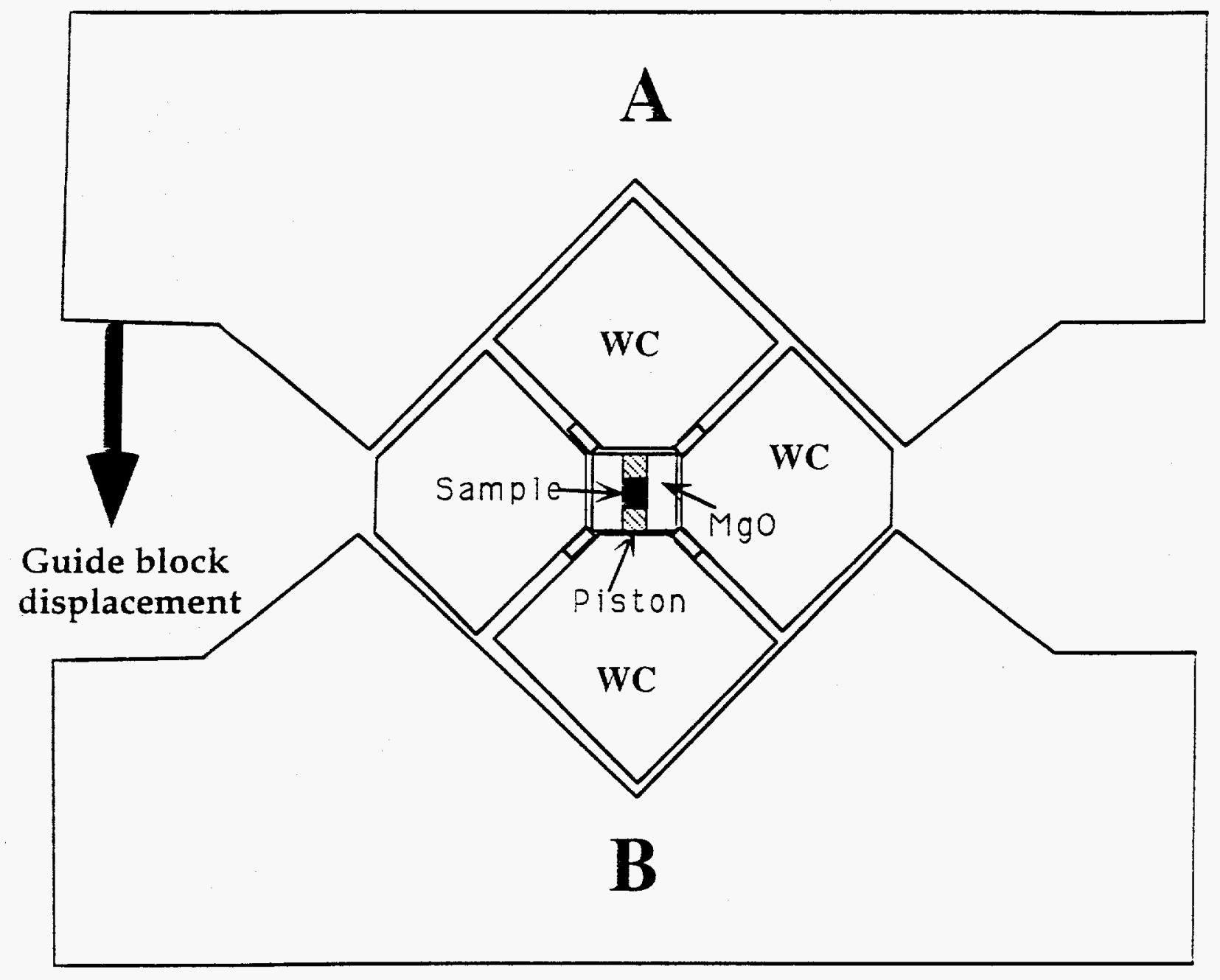

Figure 2 


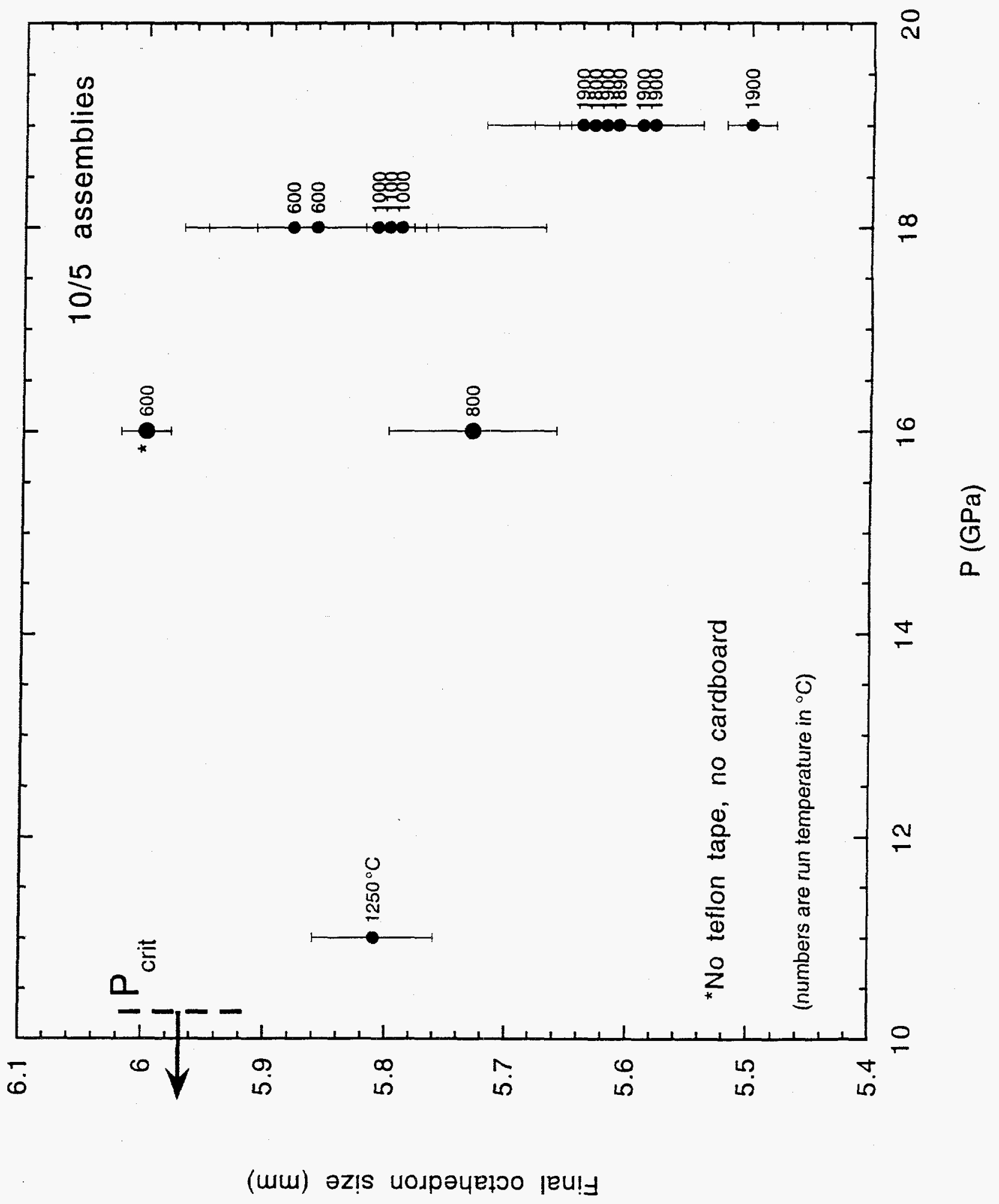




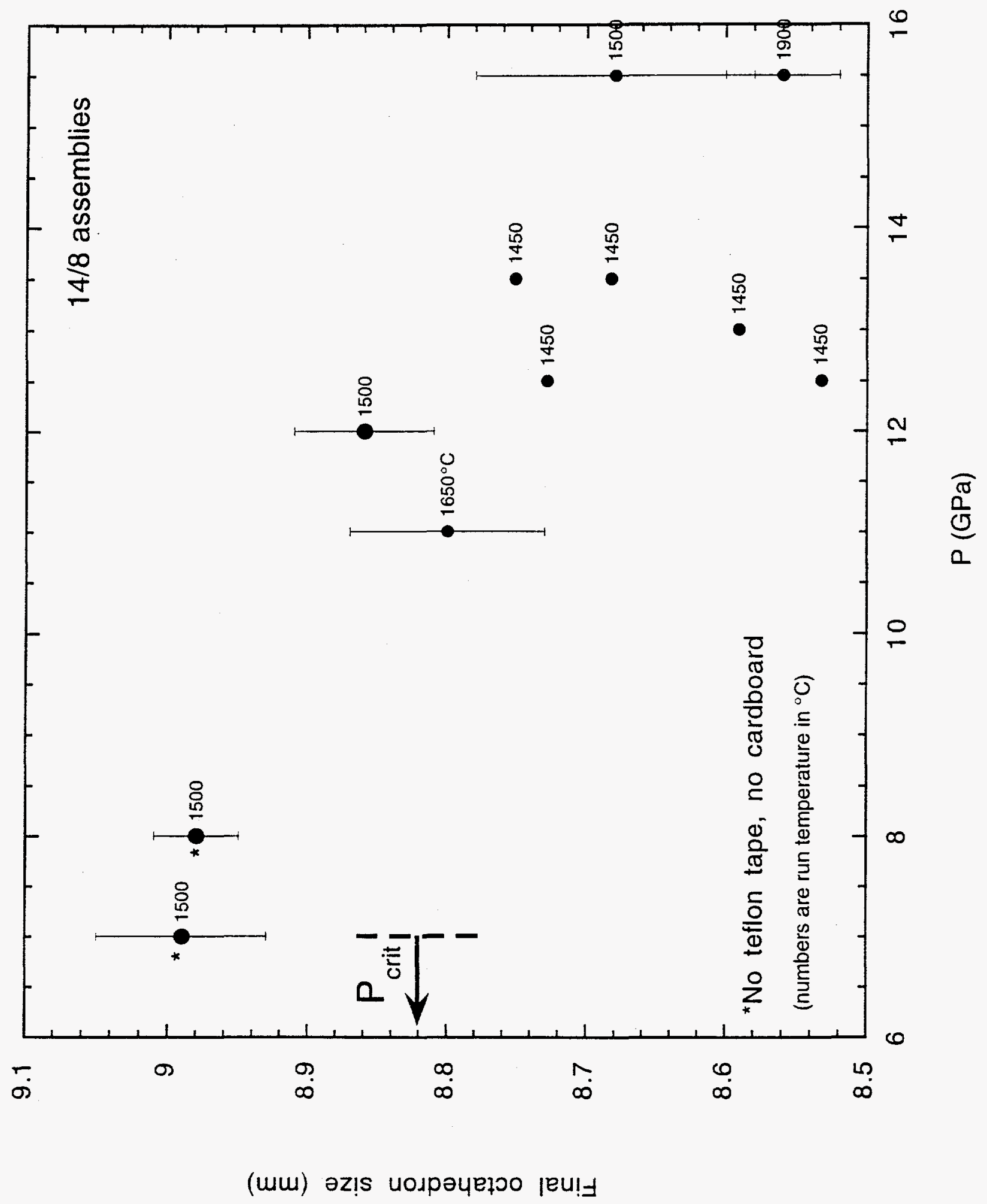




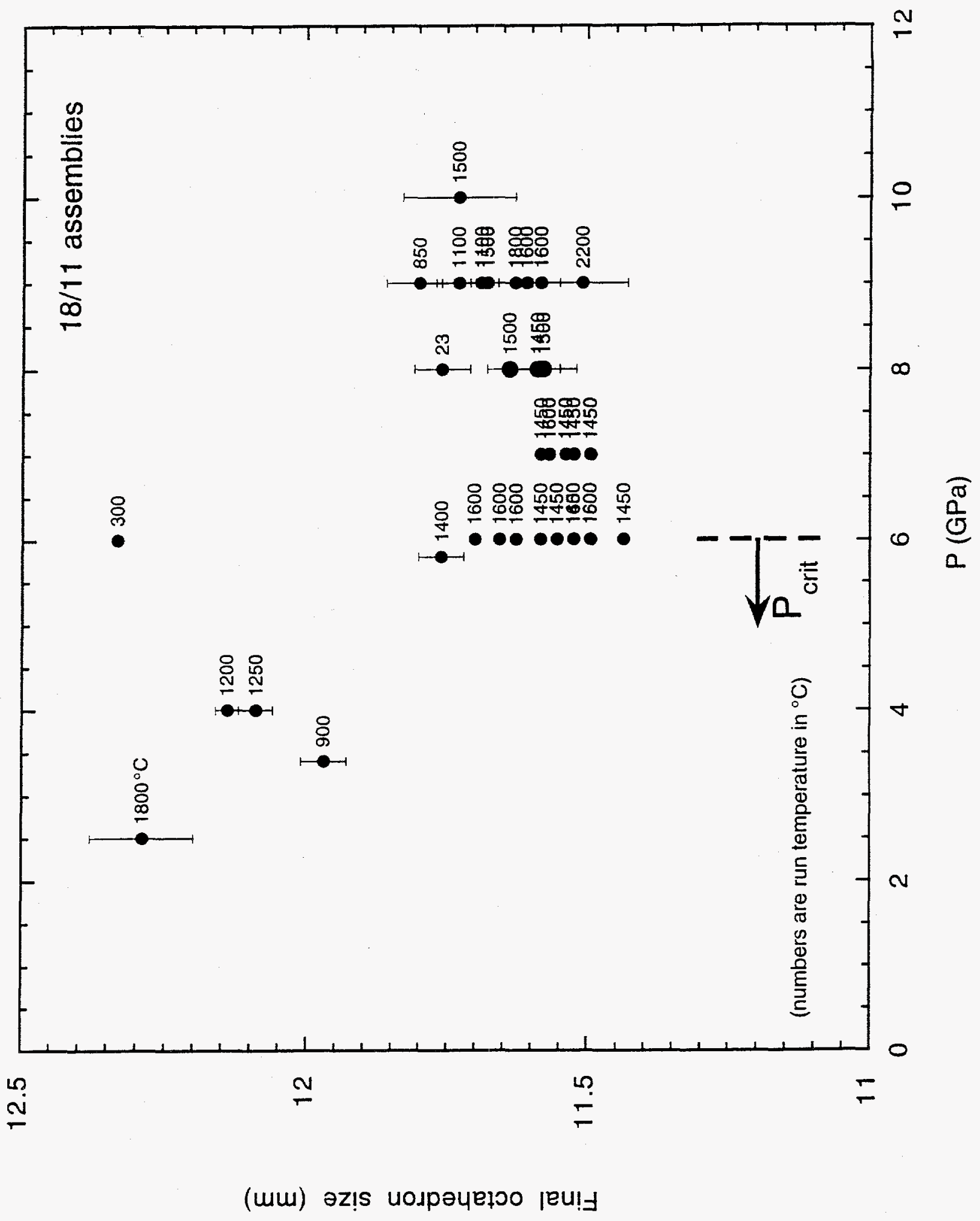




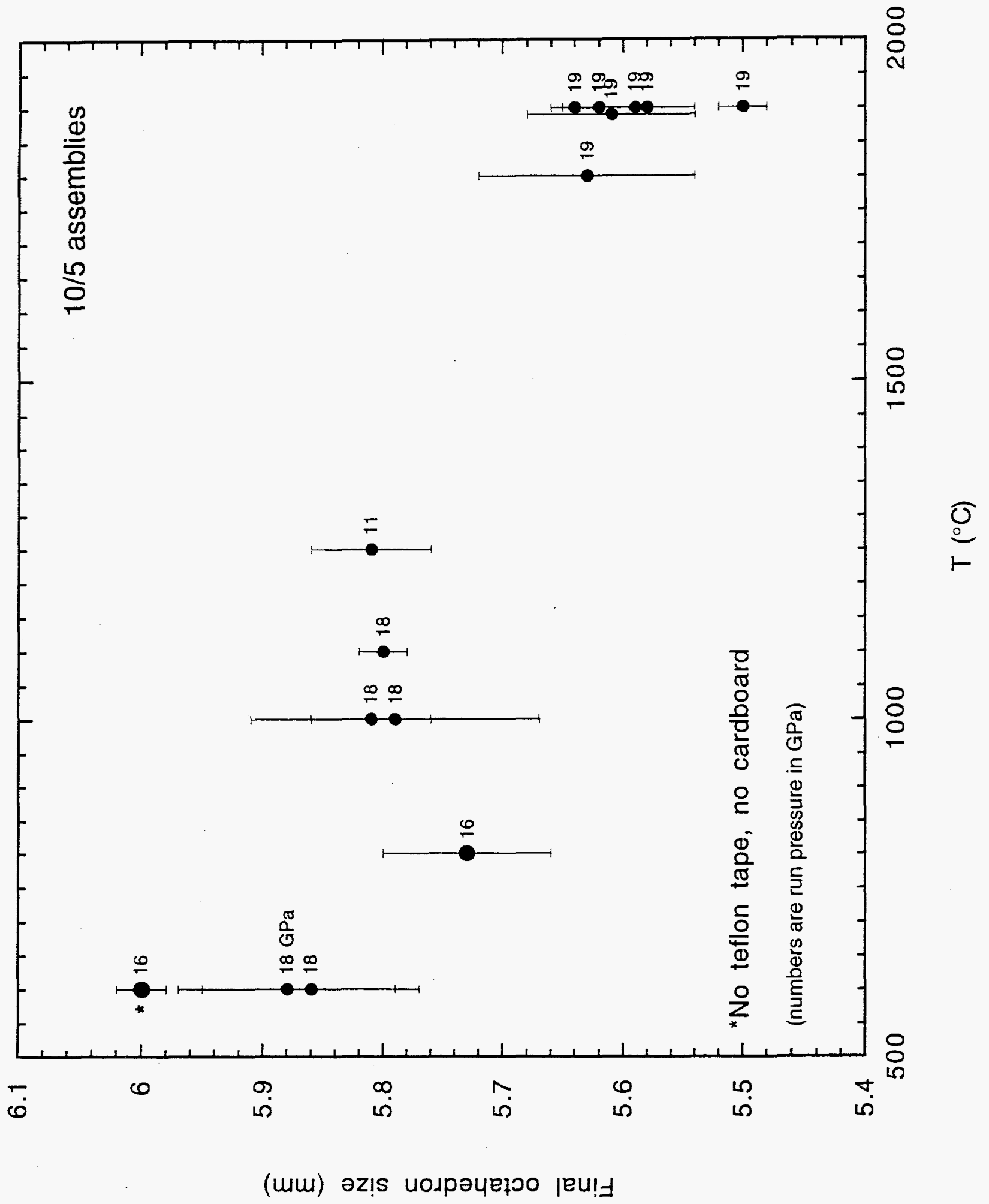




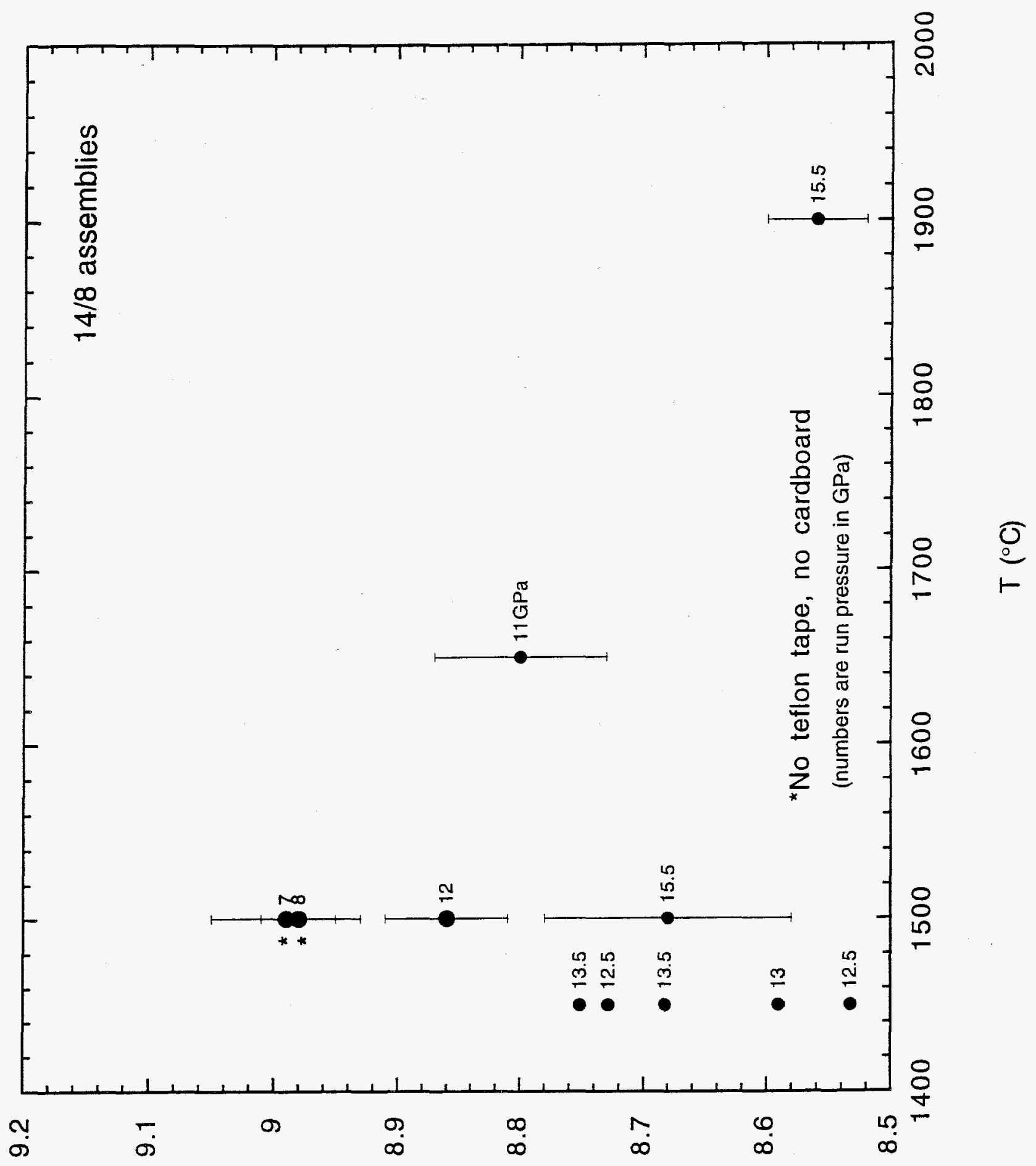

(um) әz!s uodpəyеґ๐o ןеu! 


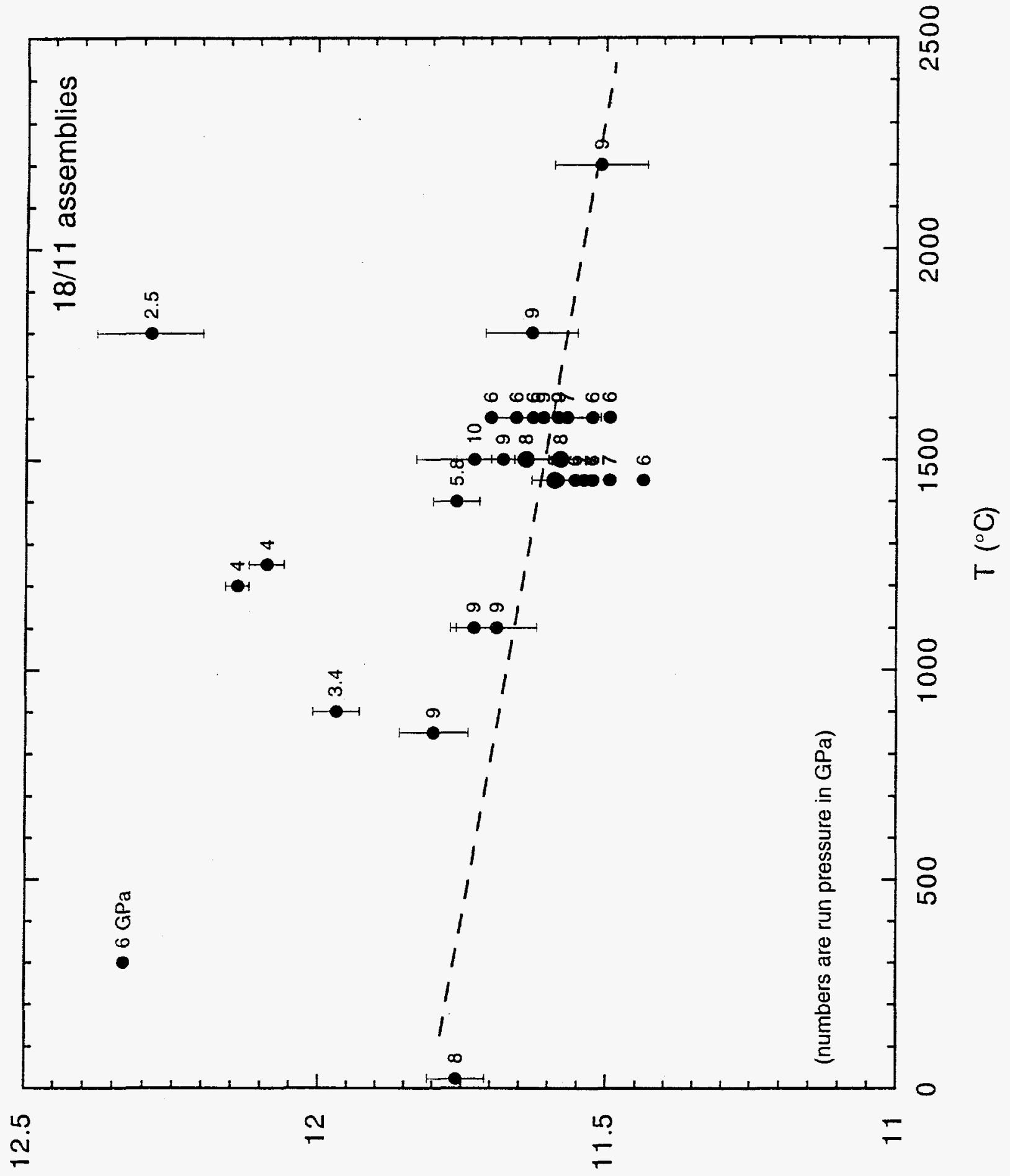

(uس) az!s uospayejoo jeu!J 


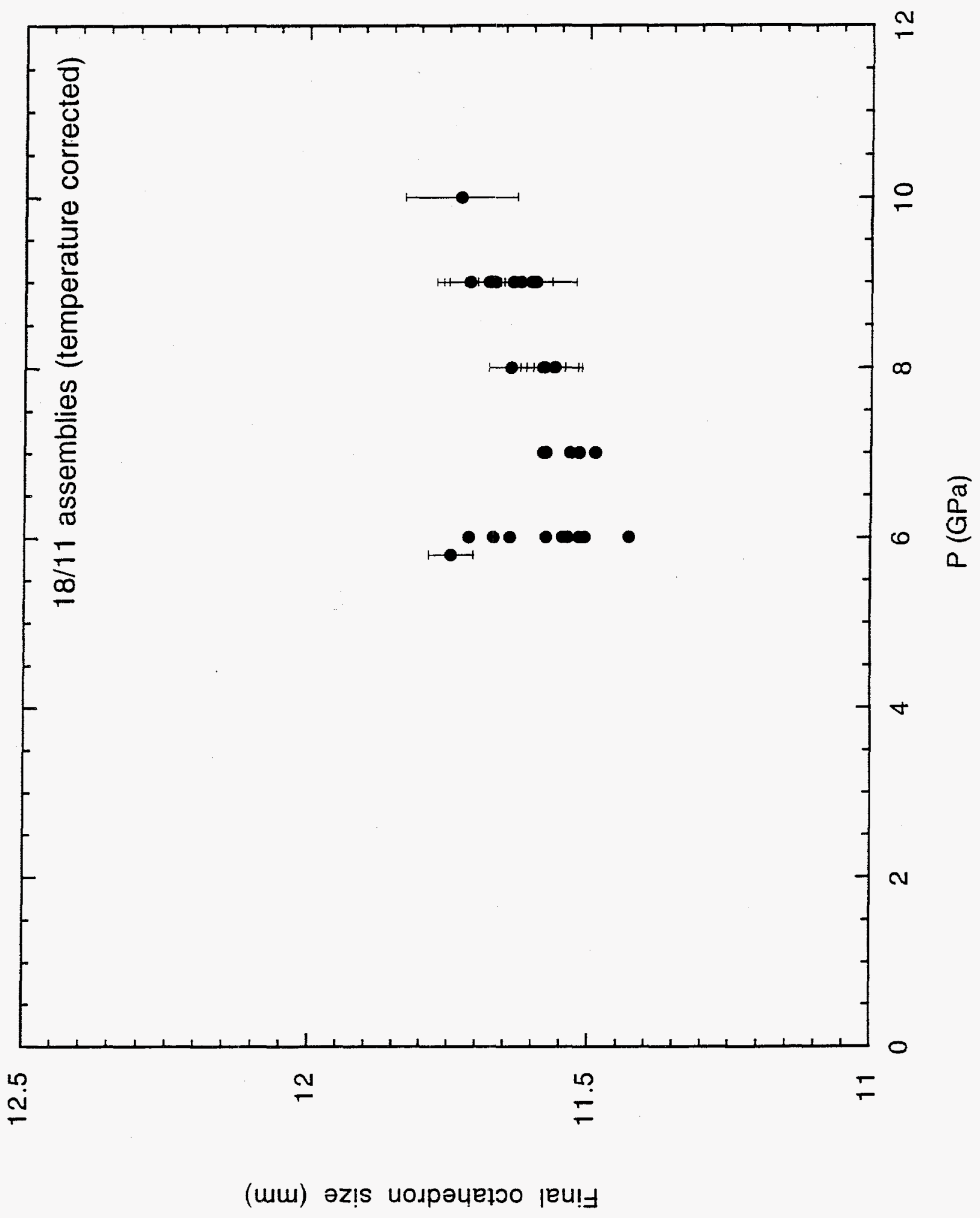




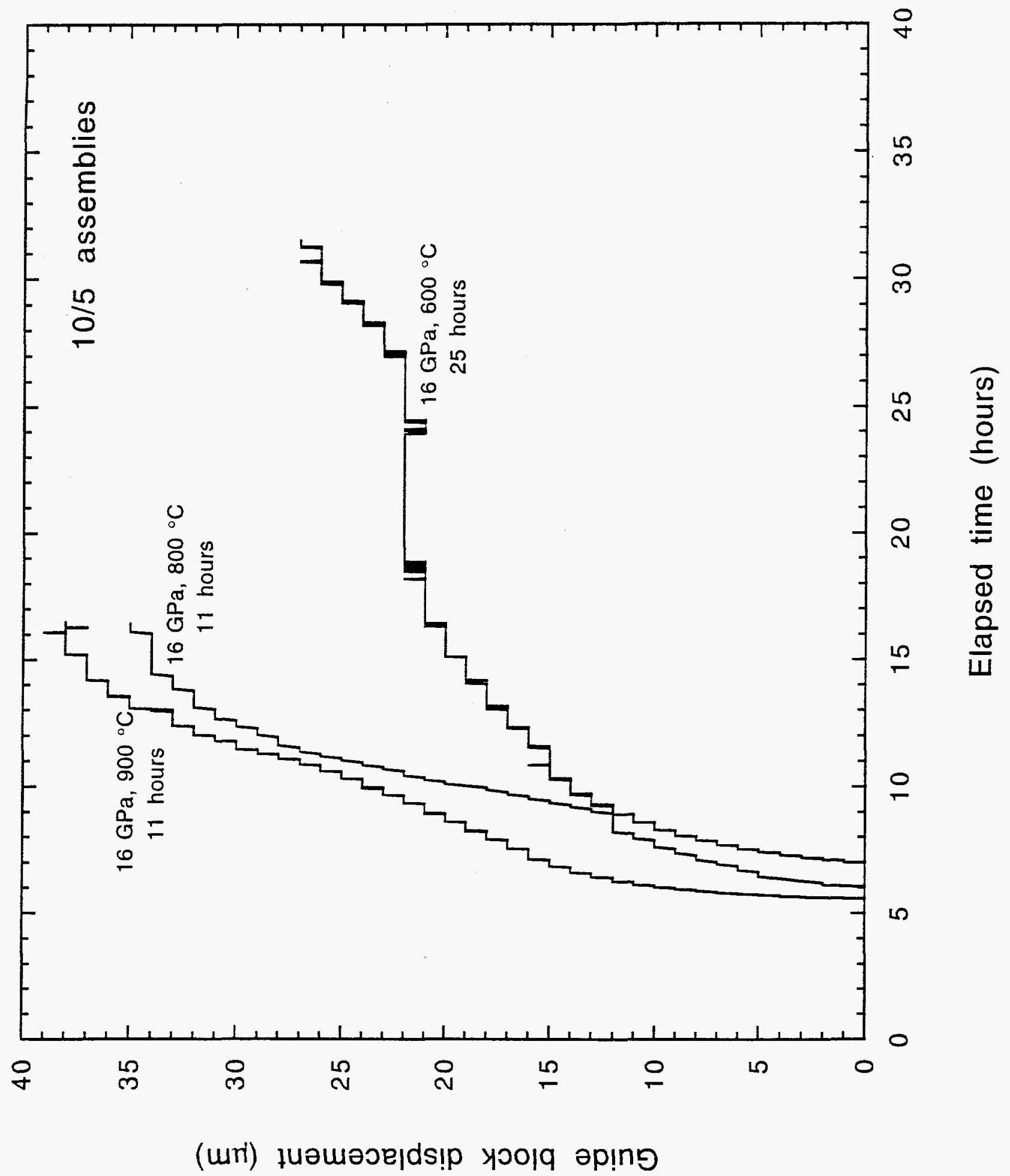




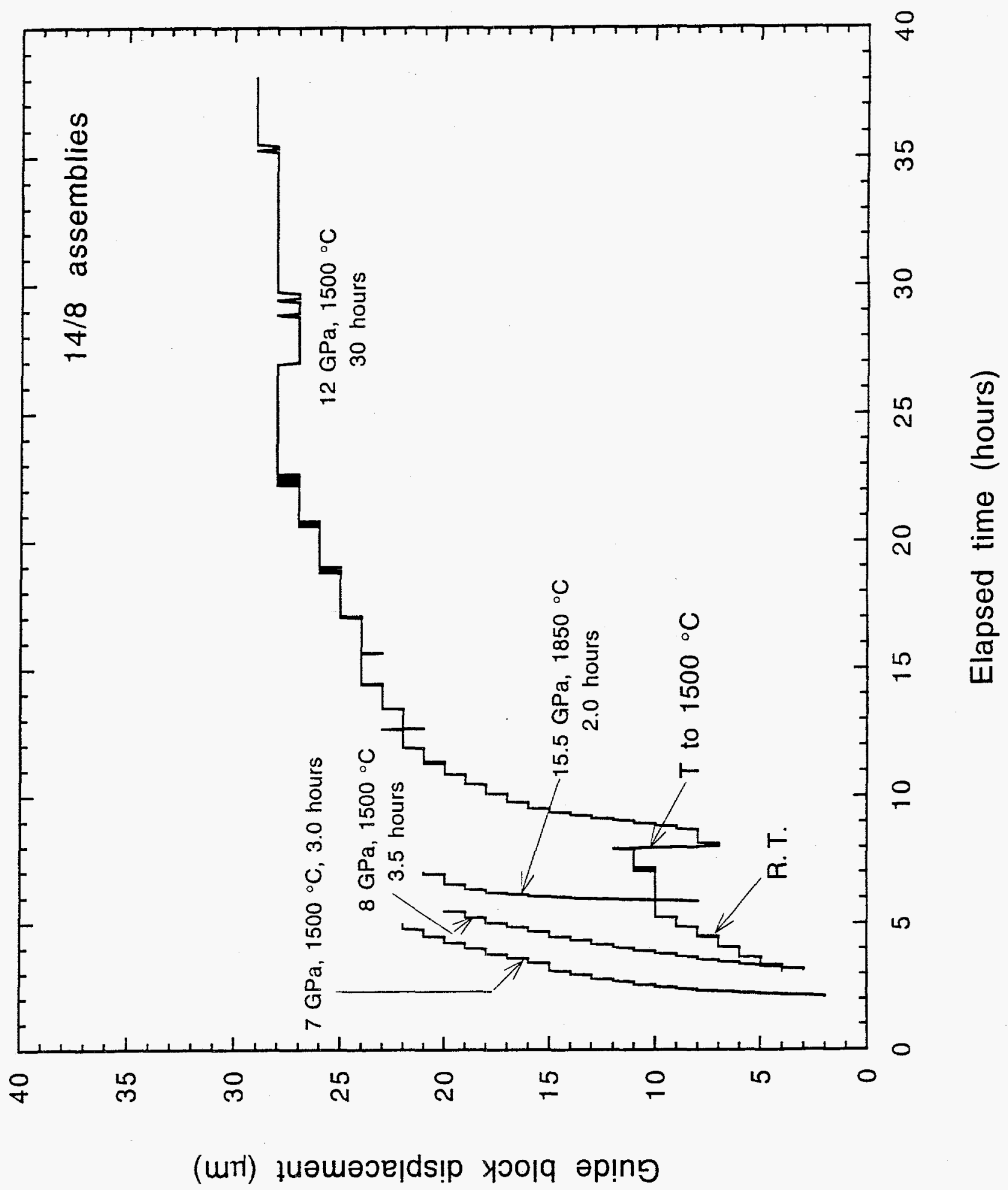




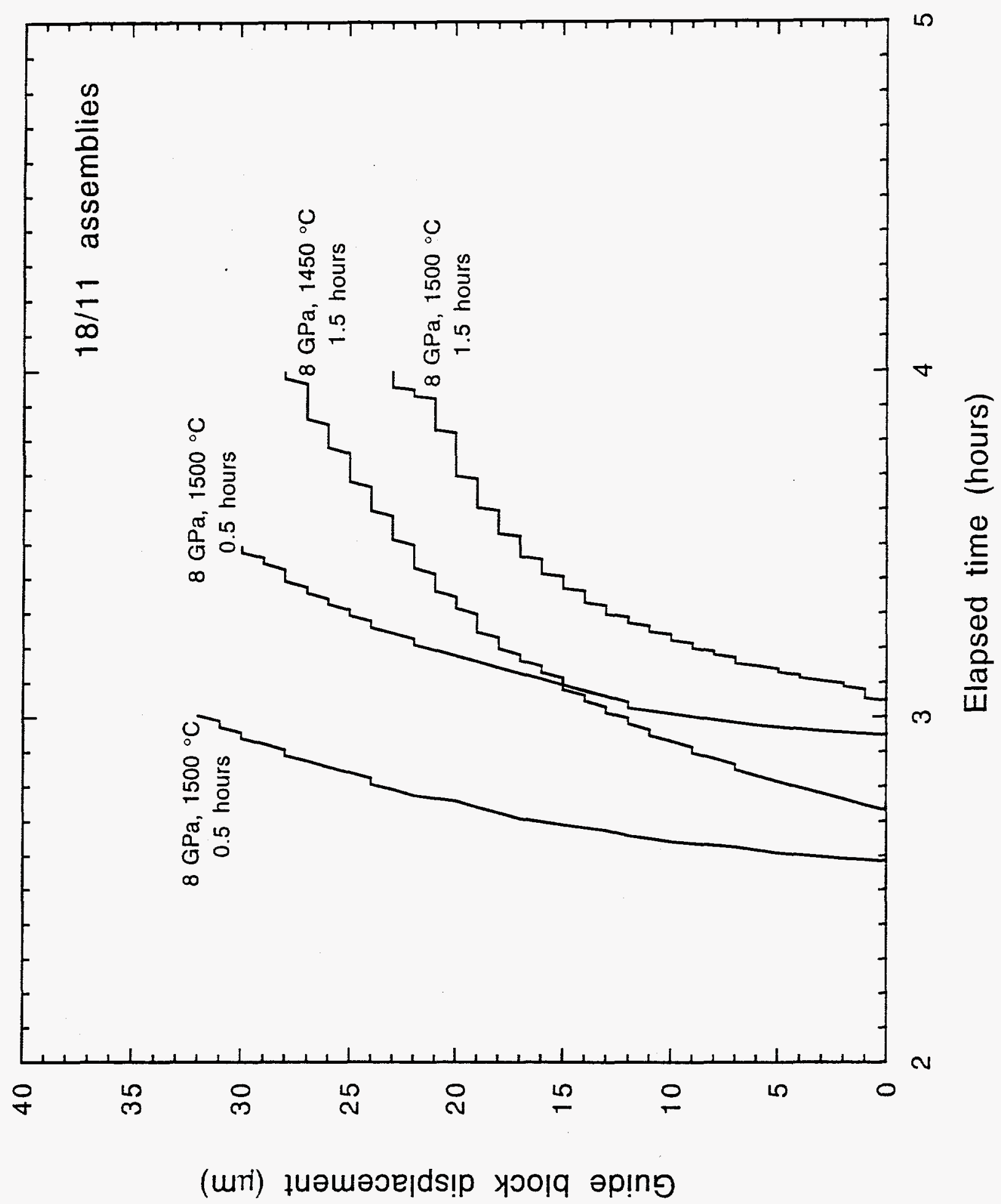




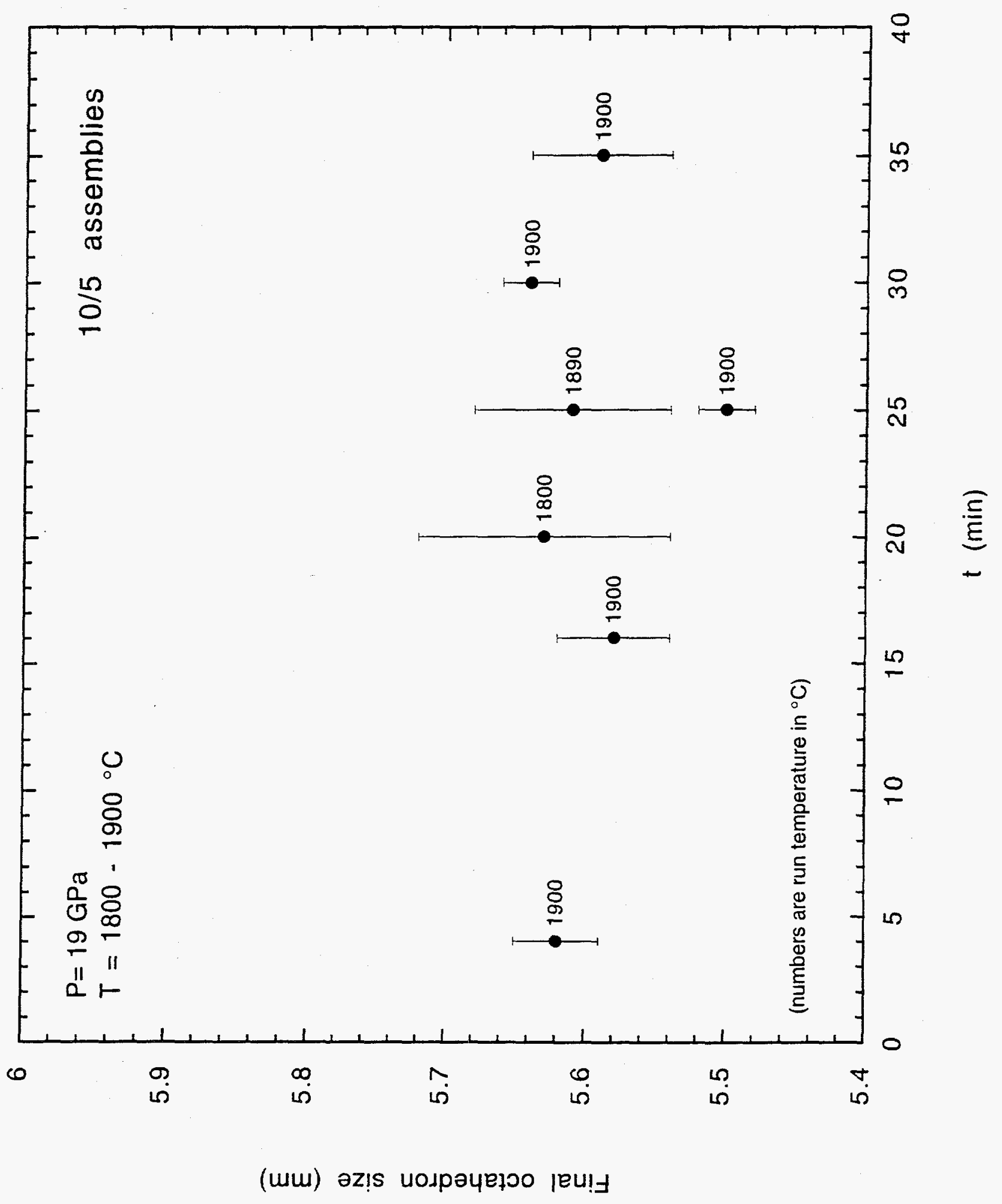

